\title{
Perception of movement in American Sign Language: Effects of linguistic structure and linguistic experience
}

\author{
HOWARD POIZNER \\ The Salk Institute for Biological Studies, La Jolla, California
}

\begin{abstract}
In order to reveal the psychological representation of movement from American Sign Language (ASL), deaf native signers and hearing subjects unfamiliar with sign were asked to make triadic comparisons of movements that had been isolated from lexical and from grammatically inflected signs. An analysis of the similarity judgments revealed a small set of physically specifiable dimeneions that accounted for most of the variance. The dimensions underlying the perception of lexical movement were in general different from those underlying inflectional movement, for both groups of subjects. Most strikingly, deaf and hearing subjects significantly differed in their patterns of dimensional salience for movements, both at the lexical and at the inflectional levels. Linguistically relevant dimensions were of increased salience to native signers. The difference in perception of linguistic movement by native signers and by naive observers demonstrates that modification of natural perceptual categories after language acquisition is not bound to a particular transmission modality, but rather can be a more general consequence of acquiring a formal linguistic system.
\end{abstract}

American Sign Language (ASL) is the visualgestural language used by deaf communities in the United States. Since the language has developed completely cutside the auditory modality, its study can provide clues both to the nature of language and to those psychological processes upon which the comprehension and production of language rest. The present article is concerned with how deaf signers and hearing subjects unfamiliar with sign perceive movements of the hands and arms that function in very specific ways in the linguistic system of ASL. By comparing perception of linguistic movement in subjects who do and who do not know the language, we can begin to uncover the ways in which linguistic categorizations are based on the perceptual constraints of the observer, and the ways in which such categorizations are more arbitrarily determined. In this way we can begin to address the correspondence between language analyzed both as a formal system

This work was supported in part by National Institutes of Health Grant HD13249 and by National Science Foundation Grant BNS79-16423 to the Salk Institute for Biological Studies. I thank Ursula Bellugi for her valuable help throughout this project, and Don Newkirk and Edward Klima for helpful discussions of the paper. Malinda Williams, Craig Will, and Mike Herrera assisted with the experiment. I thank Emilio Bizzi, John Hollerbach, and Mike Atkenson for use of and assistance with the Selspot movement-monitoring system, which digitized the hand movements presented in Figure 3. Bell Labs kindly supplied the SINDSCAL computer program. Portions of the experiment on lexical movement were reported in Sclence, 1981, 212, 691-693. Requests for reprints should be sent to Howard Poizner, The Salk Institute, P.O. Box 85800, San Diego, California 92138. and as a system with biological bases. In order to bring these issues into focus, a brief description of ASL will be presented first.

ASL is a language passed from one generation of deaf people to the next as a native language. It is a fully autonomous language with complex organizational properties not derived from spoken languages. ASL is a highly inflective language much more like Hebrew or Latin than like English (Bellugi, 1980; Klima \& Bellugi, 1979; Lane \& Grosjean, 1980; Siple, 1978; Wilbur, 1979; Bellugi \& Klima, Note 1). Like all spoken languages, ASL shows duality of patterning: basic lexical units are formed from a limited set of combining elements that are themselves essentially without meaning, and meaningful units are combined in the signed sentence by grammatical rules. However, the mechanisms by which this linguistic structure is conveyed strongly bear the mark of the modality in which the language developed.

With respect to the first level of patterning, signs from ASL are composed of three major formational parameters: configuration of the hands, movement of the hands and arms, and location of the hands relative to the body (Stokoe, Casterline, \& Croneberg, 1965). Each parameter comprises an inventory of discrete representatives that combine concurrently rather than linearly. These representatives function separately, however, to contrast minimally different signs, much as the phonemes of spoken language minimally contrast words. In the sign $\mathrm{HOME}^{1}$, for example, an O-shaped hand makes two contacts on the cheek. The sign HOME differs in form from the sign PEACH only in movement: in PEACH, the $O$ 
hand makes a circling movement on the cheek. Similarly, other pairs of signs are minimally differentiated by representatives of other formational parameters. Furthermore, the formational parameters of signs not only describe linguistic structure but are also clearly important to the way signers process signs (Bellugi, Klima, \& Siple, 1975; Newkirk, Klima, Pedersen, \& Bellugi, 1980; Poizner, Bellugi, \& Tweney, 1981).

The concurrent packaging of structural information in ASL is also apparent at the morphological level. With respect to the second level of patterning in ASL, basic signs themselves undergo inflectional processes that modify their meanings. These processes impose regular changes in form across syntactic classes of signs, and serve as a major vehicle in ASL for expressing semantic distinctions. Furthermore, inflections in ASL, as in speech, are not optional but, rather, are required in sentential contexts of the language (Klima \& Bellugi, 1979). The distinctions between lexical units and inflectional processes acting on them have also been shown to have psychological as well as linguistic validity (Poizner, Newkirk, Bellugi \& Klima, 1981). However, unlike English, which typically inflects words by adding segments to the end of a word, such as the past tense marker [ $\partial \mathrm{d}$ ] in needed, or the plural marker [s] in books, ASL inflects signs by modulating the movement and spatial contouring of the sign. Bellugi and Klima (Note 1) argued that the appropriate analysis of morphological structure in ASL is in terms of multiple tiers: an underlying lexical root, and inflectional and derivational tiers overlaid concurrently with the root. They pointed out that uninflected lexical stems are embedded in simultaneously overlaid changes in movement and spatial contouring: a sign and its inflectional marker co-occur in time. Furthermore, it appears that some of the building blocks and combinations of building blocks used to construct lexical items and inflectional processes may differ. For example, a certain inflectional process embeds sign stems in iterations along a circle of a horizontal plane; another embeds sign stems in uneven reduplicated elliptical movement. These (and other) global movement contours do not occur as movements of basic uninflected signs (Bellugi, 1980; Klima \& Bellugi, 1979).

ASL inflections mark such grammatical categories as person, number, distributional aspect, and temporal aspect. The semantic modifications entailed by these grammatical categories include pronominal reference, indication of the number of arguments of the verb (one, two, many), distributed action to the arguments of the verb (e.g., "to each," "to certain ones"), and the temporal recurrence of events (e.g., "for a long time," "regularly," "incessantly") (see Bellugi, 1980, Fischer \& Gough, 1978, Klima \&
Bellugi, 1979, and Supalla \& Newport, 1978, for a more complete description of these and other morphological processes in ASL). Importantly, these modifications of signs are transmitted by superimposed changes in the movement of signs.

Fundamentally, the present study asks three questions about the perception of movement in ASL. First, if the various movements at both the lexical and the inflectional levels are perceived in terms of a limited set of underlying dimensions, how might obtained perceptual dimensions, for deaf and for hearing subjects, relate to the linguistic dimensions that have been proposed to account for relationships in the linguistic system?

Second, do the dimensions that may underlie perception of lexical movement differ from those that may underlie perception of inflectional movement? If some perceived dimensions at the two linguistic levels differ, then data from language processing would support the linguistic analysis that suggests that formational material at the two linguistic levels may in part be different. This situation would differ from that of most spoken languages, in which the same kinds of speech sounds are used to form both basic words and their grammatical inflections, and might point to ways in which the transmission modality might shape the form that languages take.

Finally, and most importantly, does the psychological representation of movement in ASL differ between native signers and naive observers? If so, then the linguistic experience of the deaf must have, in part, determined their perception of this formational parameter. Related experiments on the perception of speech indicate that either natural nonlinearities of the auditory system or particular phonological experience can determine a speaker's perception of phonemes. As an example of the former, natural nonlinearities of the auditory system for discriminating differences in the temporal order of events have been linked to the perception of voicing contrasts in speech (Aslin \& Pisoni, 1980; Jusczyk, Pisoni, Walley, \& Murray, 1980; Pisoni, 1977). The following pattern of results serves as an example of the phonological determination of language perception. Human infants discriminate acoustic differences that cue the distinction between the phonemes $/ r /$ and $/ 1 /$ much as do Englishspeaking adults, in whose language the distinction is phonologically contrastive (Eimas, 1975). Infants and adult English speakers are much better able to discriminate the same physical difference for stimuli across the English phoneme boundary than for stimuli within either phoneme category. The distinction between $/ r /$ and $/ 1 /$, however, is not contrastive in Japanese phonology, and unlike infants and English-speaking adults, Japanese-speaking adults fail to discriminate these acoustic differences 
(Miyawaki, Strange, Verbrugge, Liberman, Jenkins, \& Fujimura, 1975). Linguistic experience has in this case modified innate auditory sensitivities. Is the modification of perception due to linguistic experience bound to the oral-auditory transmission modality? The differences between visual and auditory perception seem, after all, more striking than the similarities (Julesz \& Hirsh, 1972).

Two studies have compared perception of certain formational parameters of lexical signs in ASL by deaf signers and by naive hearing subjects; neither found differences between the two groups in the pattern of perception of these parameters. Poizner and Lane (1978) required deaf and hearing subjects to identify the location, relative to the body, at which a sign was being made. Stungis (1981) required subjects to identify and discriminate the configuration of the hand. Both studies found congruent patterns of identification and discrimination for deaf and hearing subjects, indicating no modification of perception due to linguistic experience for these sign attributes.

Location of the hand and configuration of the hand are static attributes, however, and we may well expect sign movement to be processed differently. Indeed, studies on the perception of speech have found that listeners process temporal variation in a very different manner from steady-state information. For example, precisely those speech sounds that are cued by rapid temporal changes are the ones that are perceived categorically; steady-state speech sounds seem to be perceived in terms of continuous variation (Liberman, Cooper, Shankweiler, \& StuddertKennedy, 1967). Similarly, speech sounds with rapid temporal change are generally processed more efficiently by the left rather than the right cerebral hemisphere, whereas this is not the case for steadystate speech sounds (Liberman et al., 1967; Schwartz \& Tallal, 1980). Temporal variation, indeed, is important in determining cerebral asymmetries for ASL signs as well (Poizner, Battison, \& Lane, 1979). Perception of ASL movement may likewise generally differ in nature from perception of static ASL parameters. Perhaps for movement, deaf signers will be more sensitive to some kinds of differences between stimuli than to others, depending on the role of the stimuli in the linguistic system. If the psychological representation of ASL movement does differ between native signers and naive observers, then the modification of natural perceptual categories after language acquisition would not be bound to the auditory modality, but rather could be a more general consequence of acquiring a formal linguistic system.

\section{METHOD}

\section{Subjects}

Two groups of subjects were used. The first comprised five congenitally deaf signers, of deaf parents, who learned ASL as a first language and who currently used ASL as their primary mode of communication. Their ages ranged from 20 to 24 years (mean $=22.0$ years). The second group of subjects comprised five normally hearing adults who had no knowledge of sign language whatsoever. Their ages ranged from 17 to 47 years (mean $=28.4$ years).

\section{Stimuli}

Since this study is concerned with perception of movement, a technique was used to isolate movement from sign forms in order to study movement directly. One of Johansson's (1973) methods for presenting biological motion as patterns of moving lights was adapted for this purpose. Small incandescent grainof-wheat lights were attached to the signer, and videotaping was performed in a darkened room. The brightness and contrast controls were adjusted during playback so that only the patterns of moving spots of light were visible. One light was placed on the head of the signer, directly over the spine, and other lights were placed one on each shoulder, elbow, wrist, and index fingertip. Poizner, Bellugi, and Lutes-Driscoll (1981) showed that these dynamic point-light displays convey ASL movement at both the lexical and inflectional levels quite veridically, and, indeed, do so when presented in two-dimensional as well as in three-dimensional displays. The advantage of this technique lies in its dramatic reduction of cues other than those of interest here, namely, movement and the spatial contouring of the movement path in relation to the body of the signer. The configuration of the hand, the expression on the face, and the body of the signer are not displayed, thus allowing direct focus on movement and spatial contouring.

Fifteen one-handed movements each at the lexical and at the inflectional levels were used. The lexical movements included 13 movement primes listed in Stokoe et al. (1965) that did not involve interacting movement of the two hands or finger movement only (hand internal movement). Two one-handed circular movements were added to this set. These two movements and the one circular movement listed in Stokoe et al. (1965) occurred in three distinct planes.

Signs with the following types of movements were used: supinating rotation (DIE, Figure 1a); pronating rotation (HAPPEN, Figure 1b); nodding or bending action (SHOULD, Figure 1c); upward movement (POLE, Figure 1d); downward movement (DOWN, Figure 1e); up-and-down movement (SAME-vertical plane, Figure 1f); rightward movement (FIRST, Figure 1g); leftward movement (TO-LEFT, Figure 1h); side-to-side movement (SAME-horizontal plane, Figure 1i); movement toward the signer (PICK, Figure 1j); movement away from the signer (LOOK-AT, Figure 1k); and to-and-fro movement (TWO-OFUS, Figure 11). Three circular movements were used: one in a plane parallel to the front of the signer's body (AREA, Figure $1 \mathrm{~m}$ ), one in a sagittal plane (PITY, Figure 1n), and one in an oblique plane (ALWAYS, Figure 10).

Fifteen inflections, described in detail in Klima and Bellugi (1979), were used. All occurred here with the basic sign LOOKAT and all were made with one hand. Five of these inflections marked temporal aspect (habitual, incessant, durational, iterative, continuative), seven indicated number and distributional aspect (dual, multiple, exhaustive, seriated external, apportionative external, seriated internal, apportionative internal), and three indicated referential indexing (third-person object, thirdperson 1 subject to third-person 2 object, and third-person subject to first-person object).

Figure 2 presents the 15 inflectional movements with the sign LOOK-AT. The habitual inflection (Figure 2a), meaning "to (verb) regularly," is formed by rapidly and smoothly repeating short outward movements from the signer's body. The incessant inflection (Figure 2b), meaning "incessantly," is made with even faster and shorter, but tensed, repetitions of outward movement. The durational inflection (Figure 2c), meaning "continuously," has a pattern of smooth circular repetition. The iterative inflection (Figure 2d), meaning "over and over 


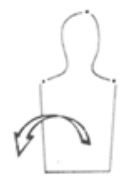

A) SUPINATING ROTATION

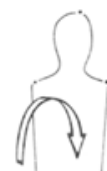

B) PRONATING ROTATION

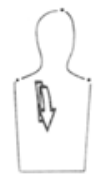

C) NODDING ACTION

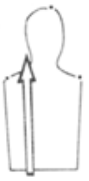

D) UPWARD MOVEMENT

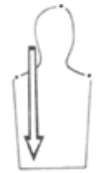

E) DOWNWARD MOVEMENT

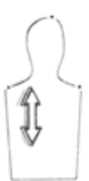

F) UP-AND-DOWN MOVEMENT

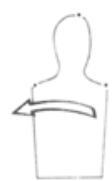

G) RIGHTWARD MOVEMENT

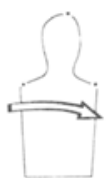

H) LEFTWARD MOVEMENT

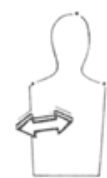

I) SIDE-TO-SIDE MOVEMENT

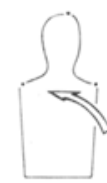

J) TOWARD

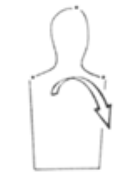

K) AWAY FROM SIGNER

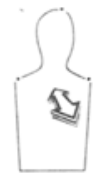

L) TO-AND-FRO MOVEMENT

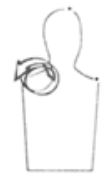

M) CIRCULAR:

FRONTAL PLANE

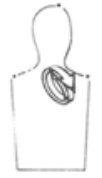

N) CIRCULAR: SAGITTAL PLANE

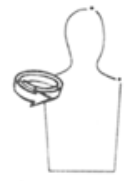

0) CIRCULAR: OBLIQUE PLANE

Figure 1. The 15 lexical movements used. Description of rightward or leftward movement is with respect to the signer, not the observer.

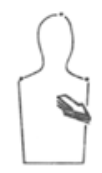

A) HABITUAL 'regularly'

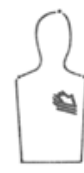

B) INCESSANT

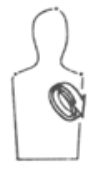

CI DURATIONAL 'continuously'

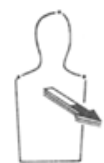

D) ITERATIVE 'over and over again'

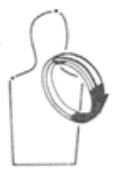

E) CONTINUATIVE 'for a long time'

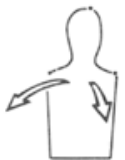

F) DUAL

'to both'

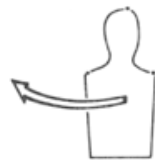

G) MULTIPLE

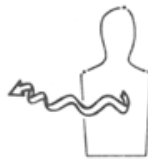

H) exhaustive 'to eoch of them'

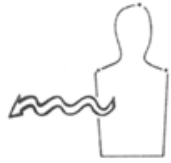

I) SERIATED EXTERNAL 'ocross a closs'

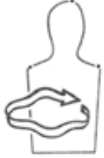

J) APPORTIONATIVE EXTERNAL

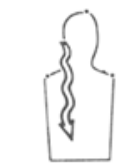

K) SERIATED INTERNAL

'with respect to

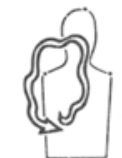

L) APPORTIONATIVE INTERNAL

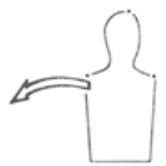

M) $3^{\text {rd }}$ PERSON OBJECT

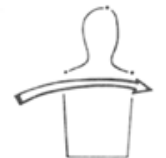

N) $3^{\text {rd }}$ PERSON 1 SUBJECT

TO $3^{\text {rd PERSON } 2 \text { OBJECT }}$ 'he to him'

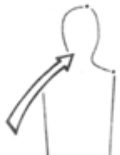

0) $3^{\text {rd }}$ PERSON SUBJECT TO $1^{\text {st }}$ PERSON OBJECT 'he to me'

Figure 2. The 15 inflectional movements used. Blackened portions of arrows indicate slow, tense movement. The 15 infections apply to verb signs. When the habitual inflection occurs with the basic sign LOOK-AT, for example, the inflected sign means "to look at regularly"; when It occurs with the basic sign GIVE, the inflected sign means "to give regularly," and so forth. 
again," and the continuative inflection (Figure 2e), meaning "for a long time," both involve long movements of uneven dynamics, having a pronounced deceleration of the hand near the point of maximal extension from the body. The iterative inflection is made with a straight outward movement, whereas the continuative inflection follows an elliptical path. The dual inflection (Figure 2f), meaning "to both," makes the outward movement of the basic sign twice, once diagonally outward to the left of the signer, once to the right. The multiple inflection (Figure 2g), meaning "to them," involves a lateral sweeping movement to the right of the signer, and the exhaustive inflection (Figure $2 \mathrm{~h}$ ) meaning "to each of them," is formed with outward movements of the hand embedded in a lateral arc to the right of the signer. The seriated-external inflection (Figure 2i), meaning "across a class," and the apportionativeexternal inflection (Figure 2j), meaning "among members of a group," have iterated movements occurring in a plane horizontal to the signer's body. The seriated-external inflection occurs along a straight line close to the signer's body; the apportionative-external inflection involves repetitions embedded in a circular path. The seriated-internal inflection (Figure 2k), meaning "with respect to internal features," and the apportionative-internal inflection (Figure 21), meaning "all over," embed repetitions along a line and a circle, respectively, in a plane parallel to the front of the signer's body. The third-person- object inflection (Figure $2 \mathrm{~m}$ ), as in "to him," involves a single outward movement to the right of the signer; the third-personsubject-to-third-person-object inflection (Figure 2n), as in "she to him," involves moving the hand contralaterally across the body between two points in the space in front of the signer in a plane horizontal with respect to the signer's body. Finally, in the third-person-subject-to-first-person-object inflection (Figure 20), as in "he to me," the orientation of the sign is turned so that the hand moves inward towards the signer's body from a point to the right of the body.

The line illustrations in Figures 1 and 2 and in the figures that follow only schematically represent the movements. Figure 3 presents the actual point-light paths of the fingertips (panel B) of the two inflected signs illustrated in panel $\mathbf{A}$ of the figure. The movement of the hand was digitized and then reconstructed in three dimensions on a computer-graphic system (see Poizner, Klima, Bellugi, \& Livingston, in press, and Loomis, Poizner, Bellugi, Blakemore, \& Hollerbach, Note 2). Figure $3 \mathrm{c}$ presents the velocity and acceleration of the hand along the movement path, over time. Figure 3 shows that the durational inflection involves a smooth repeated circular movement, whereas, the continuative inflection has a repeated elliptical movement in which the hand moves very rapidly during the outward and downward portion of a cycle, rapidly decelerates, turns around, returns to the starting position, and begins a new cycle.
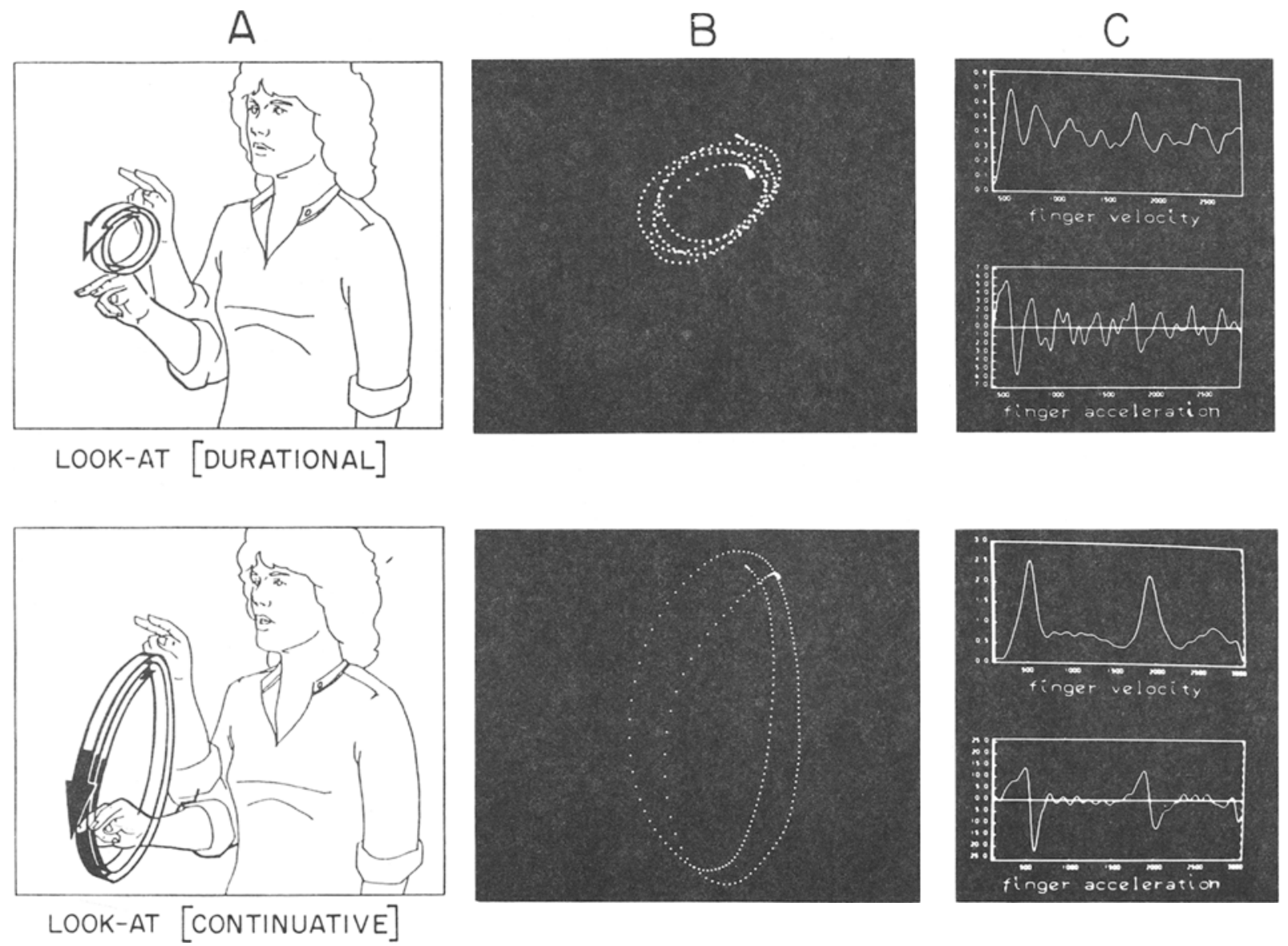

Figure 3. Line drawings of two inflected signs (A) together with computer-graphic reconstructions of the actual movement path of the hand (B) and the associated temporal profiles (C). Velocity is given in meters/second, acceleration in meters/second ${ }^{2}$, and time in milliseconds. 


\section{Design and Procedure}

The task involved triadic comparisons of either lexical or inflectional movement. An incomplete balanced design was used to reduce to a manageable size the number of triads that a subject would have to judge. Levelt, Van De Geer, and Plomp (1966) have developed such a design for triadic comparisons of 15 stimuli having the following properties: four blocks of 35 triads are presented. Within each block of triads, all possible pairs of the 15 stimuli occur once. These 105 pairs are distributed over 35 triads, with each stimulus present in seven different triads. Furthermore, each pair of stimuli occurs with a different third member in each of the four blocks of triads. Triads for the 15 lexical and for the 15 inflectional movements of the present study were constructed following the lists published in Levelt et al. (1966, p. 166). The method of triadic comparisons is particularly useful for the present study because it allows both signers and nonsigners to easily make comparisons among the same stimuli using the same responses. The subjects made a single judgment for each triad, simply deciding which two of the three stimuli were most similar. The subjects were supplied response booklets containing, for each triad, the three numbers 1,2 , and 3 arranged on the page in the form of an equilateral triangle. These numbers corresponded to the first, second, and third stimulus of the triad, respectively. The subjects indicated which two stimuli of the triad they considered most similar by circling the corresponding two numbers in the response booklet.

In order to get a measure of the reliability of subjects' judgments, each subject was run on each of the four blocks of lexical and inflectional movement twice. The order of presentation of the four blocks was independently randomized for each subject within each replication of lexical and inflectional movement. Order of presentation of each replication of lexical and inflectional movement was counterbalanced across subjects.

A deaf, fluent ASL signer with point-lights attached was videotaped making all stimuli (Sony AV3650 videotape recorder). Stimulus durations varied slightly depending upon the normal duration of the movement; however, in order to make stimulus durations roughly equal, repeated movements of long duration were repeated only as many times as would be necessary in sentential context rather than the many times that would occur in citation form. The signer, paced by a flashing metronome (Seth Thomas E962-000), made stimuli approximately $1 \mathrm{sec}$ in duration, with $1.5 \mathrm{sec}$ between members of a triad and $6 \mathrm{sec}$ separating triads.

The deaf subjects were instructed in ASL, on videotape, and the hearing subjects were given spoken-English instructions. Eight practice trials preceded each test tape to make sure that the subjects understood the task. Stimuli were presented on videotape (Sony AV3650 videotape recorder), with subjects seated approximately $2.5 \mathrm{ft}$ from the TV monitor (Sony CVM 131). Each subject was run in four separate 45-min sessions.

\section{Data Reduction}

Multidimensional scaling provides a geometric model of the psychological representation of a stimulus array by representing the stimuli as points in a multidimensional space (Carroll \& Arabie, 1980; Kruskal, 1964a, 1964b; Shepard, 1962a, 1962b, 1980). The distance separating any two stimuli in the spatial solution corresponds to the judged similarity of that pair, and, hence, the closer together two stimuli are in the spatial solution, the more similar they appear to be to the observer. Carroll and Chang's (1970) individual differences scaling model, implemented with the SINDSCAL computer program (Pruzansky, Note 3) was used in the present study. Weights that reflect the importance or salience of a given dimension for a given subject are recovered. Thus, although the model produces a group or average space for all the subjects, the weights provide a measure of what aspects of that space apply to a given subject. A weight of zero, for example, would indicate that a particular dimension simply had no relevance for a given subject.
The fit between the scaling solution and the obtained similarity scores is captured by the percentage of variance in the data accounted for by the scaling. Finally, unlike the nonmetric multidimensional scaling procedures, individual differences scaling provides a mathematically preferred orientation of the axes of the solution, and, indeed, the axes or dimensions have generally been found to correspond to psychologically significant processes (Carroll \& Chang, 1970; Wish \& Carroll, 1974).

A single scaling combining data from both deaf and hearing subjects is used, because it provides a much stronger test of whether perception differs between deaf and hearing subjects than do separate scalings of judgments of the two groups. If deaf and hearing subjects indeed differ, then they will be separated in one and the same scaling solution based solely on their judgments of movement similarity. A single scaling combining data from both groups allows for the possibility of differential degrees of overlap between groups on any dimension, rather than simply assigning a dimension to a group or not. In separate scalings, dimensions that were different for the groups as wholes could be obtained, but individual subjects from the groups could overlap without one's ever knowing. The use of a single pooled scaling makes explicit the precise degree of overlap, or lack of overlap, between groups.

\section{RESULTS}

Similarity matrices were constructed for each replication of the four blocks of lexical and of inflectional movement for each subject. The similarity of any pair of movements was determined by the frequency with which that pair was judged as most similar in the triads in which it occurred. These matrices served as input to the SINDSCAL program.

\section{Lexical Movement}

In order to evaluate initially whether deaf subjects perceived relationships among lexical movements of ASL differently from the way hearing subjects did, a discrete method of grouping subjects was performed. First of all, the similarity matrix for each replication of each subject (deaf and hearing) was correlated against every other similarity matrix. The resulting correlation matrix specifying relationships among subjects was then hierarchically clustered by Johnson's (1967) HICLUS procedure (complete-link option) (also see Hartigan, 1975). Figure 4 presents this clustering. The terminal nodes of the tree represent

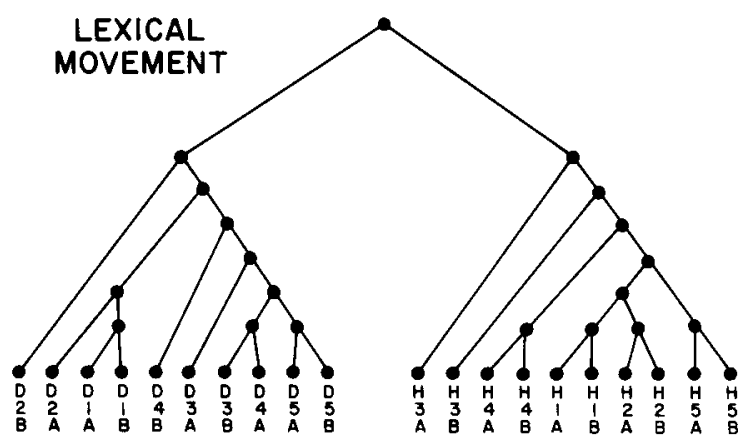

Figure 4. Hierarchical clustering of intersubject correlations of similarity matrices for lexical movement. 
each replication (A or B) of each deaf (D1 through D5) and each hearing (H1 through H5) subject. Strikingly, the clustering separated the subjects into two distinct groups, based entirely on whether the subjects were deaf or hearing. Clearly, deaf and hearing subjects perceive lexical movement in different ways.

SINDSCAL scalings on all 20 matrices were performed in one through six dimensions. The fourdimensional solution was selected because it accounted for $70.0 \%$ of the variance in the data, a magnitude only slightly less than the $76.9 \%$ of variance accounted for by the six-dimensional solution. Within the four-dimensional solution, Dimension 1 accounted for $43.8 \%$ of the variance, Dimension 2 , $10.7 \%$, Dimension 3, 8.8\%, and Dimension 4, 6.7\%.

Figures $5 \mathrm{a}$ and $5 \mathrm{~b}$ present the four-dimensional SINDSCAL group solution. The location of each stimulus in the spatial configuration is at the center of each of the schematized figures representing the 15 movements. Where figures overlap, asterisks indicate the location of figures marked by arrows. Figure 5a presents Dimension 2 against Dimension 1. The dashed lines in the figure were positioned by the author, rather than by the scaling program, in order to help make clear the interpretation of the configuration. Stimuli on the left-hand side of Dimension 1 all have repeated movements, whereas each stimuli to the right of the dashed vertical line has a single, unrepeated movement. Dimension 1 was thus labeled "repetition," capturing the fact that the lexical movements were first separated on the basis of whether or not they were repeated. Projections along Dimension 2 fall into three broad categories. The four stimuli in the upper portion of the figure all occur in a plane parallel to the front of the signer's body, whereas the seven stimuli in the lowermost portion of the figure all occur primarily in a horizontal plane, perpendicular to the front of the signer's body. Finally, the four stimuli projecting to the center of Dimension 2 occur either in a sagittal plane (movement in PITY and in YOU-AND-1) or in a plane oblique with respect to the signer's body (movement in ALWAYS and in SHOULD). Dimension 2 was thus labeled "plane."

Figure $5 b$ presents the configuration in Dimension 4 versus Dimension 3. Stimuli to the left of the vertical dashed line in the figure are predominantly straight in path. As we move further to the right along Dimension 3, stimuli become increasingly arced, until movements become circular for stimuli at the far right of the figure. In order to measure the degree of "arcness" in the actual stimulus items, the seven occurrences of each stimulus from one block of trials were first traced directly from the video monitor, videofield by videofield. The degree of arcness of the movement of the hand in each of these tracings was then taken by measuring the maximal deviation of the movement from the line connecting the begin-
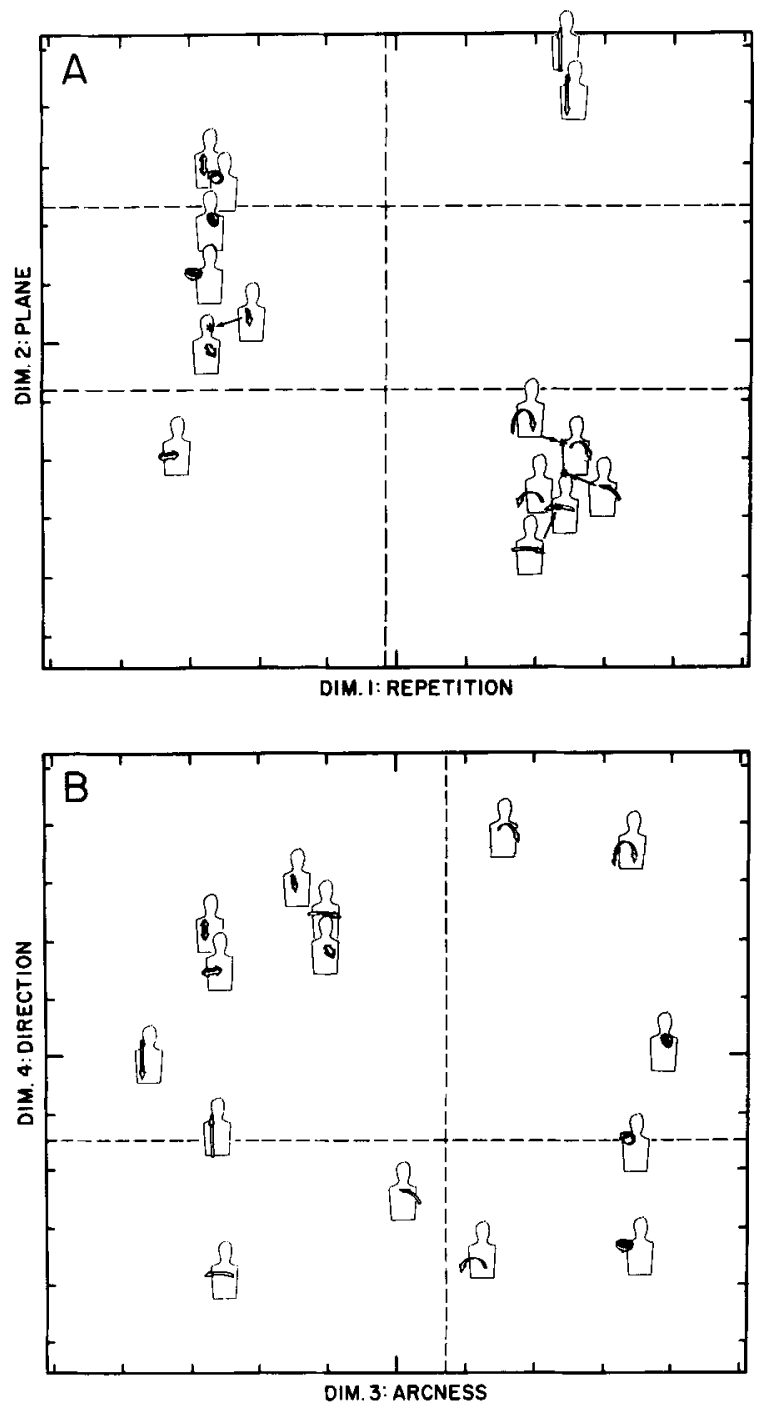

Figure 5. Configuration of stimull in the SINDSCAL solution for lexical movement. (A) Dimenuion 2 versus Dimension 1. (B) Dlmension 4 versus Dlmension 3.

ning and ending points. The mean values of arcness for each of the 15 movements were then correlated against the coordinates of each of the movements along Dimension 3 of the scaling solution. The correlation was a very substantial $r=.91, p<.01$, indicating that Dimension 3 reflected variation in the degree of arcness of the movement forms. Dimension 3 was thus labeled "arcness."

With respect to Dimension 4 , stimuli below the horizontal dashed line in Figure $5 \mathrm{~b}$ all have movements directed toward the left of the TV screen, whereas stimuli above the horizontal dashed line all have movement components toward the right of the TV screen. In order to measure the degree of directional movement in the stimulus items, a ruled grid was placed over the field by field-tracing each stimulus item from one block of trials. The grid was 
aligned with the signer's shoulders and head and the degree of leftward or rightward displacement of the hand from its initial point was measured. The mean values of the degree of rightward or leftward displacement of each of the 15 movements were then correlated against the coordinates of each of the movements along Dimension 4 of the scaling solution. The correlation was a substantial $r=.86, p<$ .01 , indicating that Dimension 4 reflected variation in the degree of rightward or leftward displacement of the movement forms. Dimension 4 was thus labeled "direction."

Figure $5 a$ and Figure $5 b$ presented the group SINDSCAL stimulus configuration incorporating both deaf and hearing subject matrices. We now turn to the weightings of different subjects on each dimension and see in Figure 6 a very different pattern of weights for deaf and for hearing subjects. The figure shows the mean weights of deaf (open circles, dashed line) and hearing subjects (filled circles, solid line) for each dimension of the solution. Standard errors of the means are presented above and below each point. Figure 6 indicates that the deaf subjects heavily weighted Dimension 1 (repetition) of the solution, moderately weighted Dimension 3 (arcness), and negligibly weighted Dimensions 2 and 4 (plane and direction). The hearing subjects, on the other hand, provided moderate weights of all four dimensions.

A mixed-design analysis of variance was performed on the weights obtained for deaf and hear-

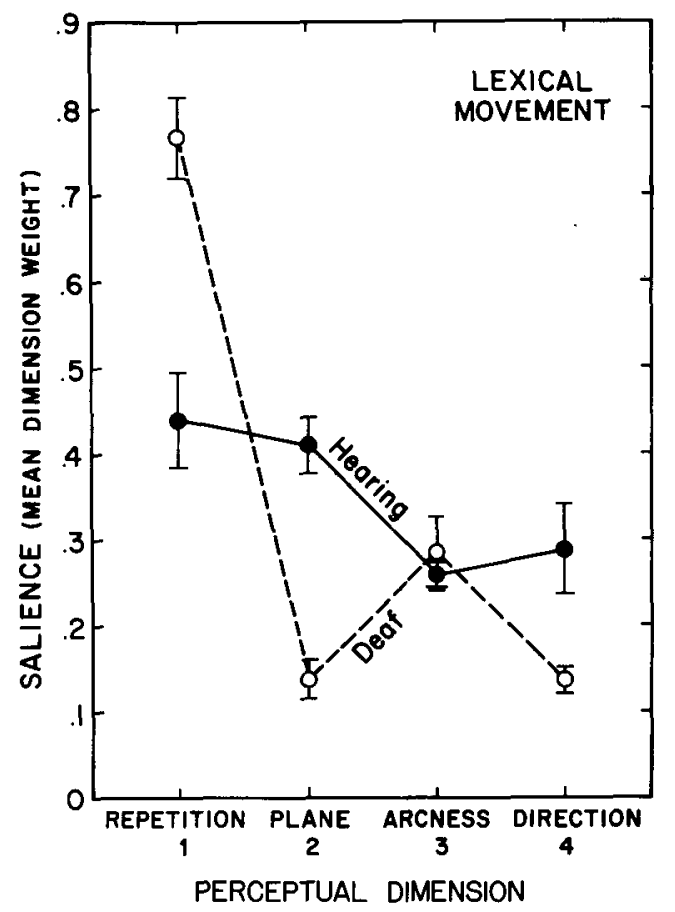

Figure 6. Perceptual allience of each dimendion of the scalling solution of lexteal movement for deaf wubjects (dashed line) and for hearing subjectu (colld line). ing subjects (two replications per subject) across the four dimensions. The analysis yielded, first of all, a significant effect of dimension $[F(3,3)=16.4$, $\mathrm{p}<.025$ ], indicating that, overall, some dimensions were more highly weighted than were others. Second, deaf and hearing subjects did not differ significantly in the overall magnitude of weights applied $[F(1,8)=$ .80 , n.s.]. Finally, and most interestingly, there was a highly significant interaction between the weights of deaf and hearing subjects across the four dimensions $[F(3,24)=8.9, p<.001]$, reflecting the differential relevance or salience of dimensions to subjects in each group. ${ }^{2}$

Individual subject variation and the reliability of the pattern of dimension weights are presented in Figure 7. Each replication (denoted by an A or a B in the figure) of each hearing (H) and deaf (D) subject is represented. The combined weight for a given subject on two dimensions is equal to the square root of the sum of his squared weights on those dimensions (Wish \& Carroll, 1974). Figure 7 plots the combined weight of each subject on Dimensions 2 and 4 against the combined weight of each subject on Dimensions 1 and 3. First of all, we notice that with only one exception (H2A), the deaf subjects simply do not overlap with the hearing subjects in their pattern of weights on these dimensions. The deaf subjects weight Dimensions 1 and 3 very highly, whereas virtually all hearing subjects weight Dimensions 2 and 4 more highly than does any deaf subject. In the second place, the figure shows that the pattern of weights for a given subject is highly reliable, as evidenced by the closeness of the points for the two replications of each subject. Furthermore, the one exception (H2A) to the nonoverlapping distributions of the deaf and hearing subjects in Figure 7 occurred precisely for that subject (H2) who had the least reliable pattern of dimension weights.

\section{Inflectional Movement}

SINDSCAL runs were performed in one through six dimensions on the 20 similarity matrices derived from both the replications of judgments of inflectional movement by each of the 10 subjects (deaf and hearing). The four-dimensional solution was again selected, as it accounted for $71.3 \%$ of the variance in the data, a magnitude only slightly less than the $76.6 \%$ of the variance accounted for by the six-dimensional solution. Within the fourdimensional solution itself, Dimension 1 accounted for $24.3 \%$ of the variance, Dimension $2,19.9 \%$, Dimension 3, 16.3\%, and Dimension 4, $10.7 \%$.

Figure 8a and Figure $8 \mathrm{~b}$ present the group solution for the inflectional movements. Figure 8a shows the configuration for Dimension 2 versus Dimension 1. Stimuli fall into four categories along Dimension 1. The four leftmost movements in the figure are all single-cycle, nonrepeated movements. 


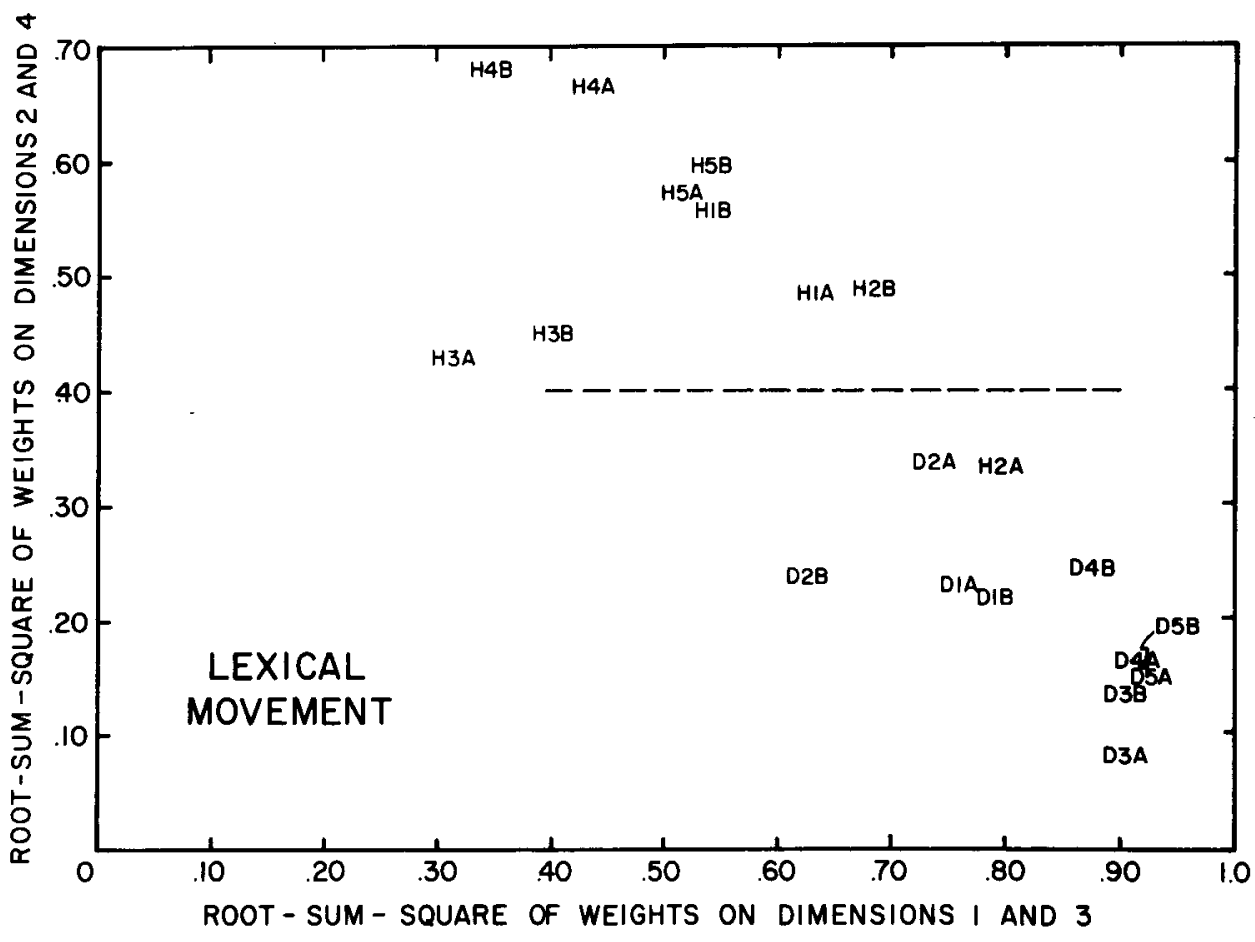

Figure 7. Root sum squares of subject weights on Dimensions 2 and 4 versus root sum squares of of subject weights on Dimensions 1 and 3.

The single stimulus in the second division from the left of the figure (dual) has exactly two repetitions. The five stimuli projecting along the middle of Dimension 1 have a movement cycle that is repeated at least once. These five stimuli are inflections for temporal aspect. Finally, the five rightmost movements along Dimension 1 are all single-cycle movements that have numerous repetitions of a movement within various spatial displacements. The entire cycle is not repeated; and these movements are inflections for distributional aspect. Thus, the 15 movements fall along Dimension 1 into those with single movements, with exactly two movements, with movements reduplicated across cycles, and with movements iterated within a cycle. Dimension 1 was thus labeled "cyclicity." Cyclicity differs from the lexical dimension repetition in that it comprises four distinctly different types of articulation, whereas repetition has only two values, single and repeated.

The stimuli below the horizontal line in Figure 8 are made in a sagittal plane, whereas the other stimuli are not. The only possible exception to this categorization is seriated internal, which has iterated movements downward along a line in a plane parallel to the front of the signer's body. However, since a line does not uniquely determine a plane, this movement could be described as occurring in a sagittal plane also. Nonetheless, the main component of the movement in seriated internal oc- curs along a line that moves downward in front of the signer rather than outward along a sagittal axis. Dimension 2 was labeled "displacement," reflecting the division of movements into those primarily along a sagittal axis from those displaced from that axis. Interestingly, also, those five movements along the sagittal axis are all inflections for temporal aspect, whereas the other 11 movements convey person, number, and distributional aspect.

Figure $8 \mathrm{~b}$ presents the configuration in Dimension 4 versus Dimension 3. Movements fall into two categories along Dimension 3. Those to the left of the vertical dashed line have movement components directed toward the left of the TV screen. The stimuli projecting to the right of the vertical dashed line in Figure 8b, however, generally move to the right of the TV screen. The rightward or leftward movement of the seven occurrences of each inflection from one block of stimuli was measured in a manner similar to that described for measuring the direction of lexical movement. The mean displacement of each inflection to the signer's right or left was then correlated against the coordinates of the inflections on Dimension 3 of the scaling solution. The correlation was a substantial $r=.82$, $\mathrm{p}<.01$, indicating that Dimension 3 reflected variation in the degree of rightward or leftward displacement of movement forms. Dimension 3 was therefore labeled "direction."

Stimuli along Dimension 4 seem to fall into two 

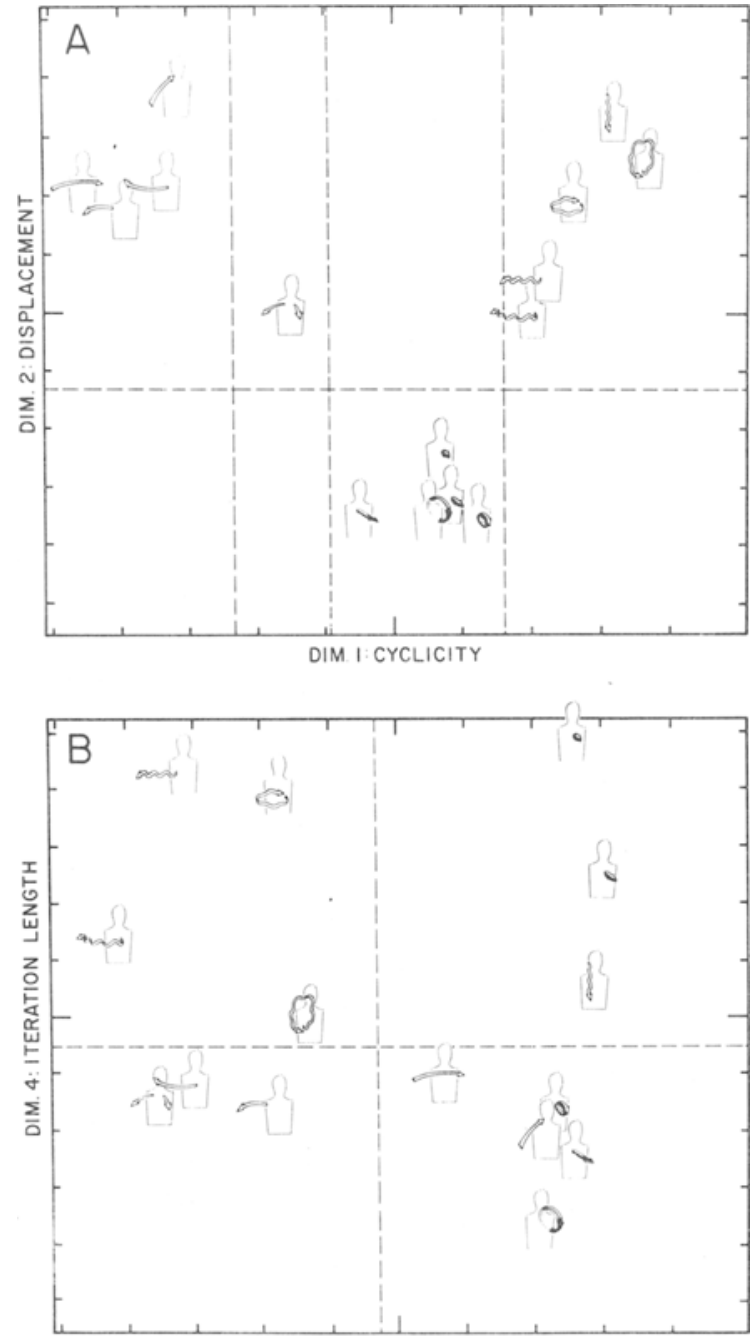

DIM. 3: DIRECTION

Figure 8. Configuration of stimull in the SINDSCAL solution for inflectional movement. (A) Dimension 2 versus Dimenaion 1. (B) Dimension 4 veraus Dimension 3.

classes. Those movements above the horizontal dashed line in Figure $8 \mathrm{~b}$ have a very short path movement, whereas movements below the horizontal line in Figure $8 \mathrm{~b}$ have longer path movements. Dimension 4 was thus labeled "iteration length," reflecting the separation of movements into two groups on the basis of length of stem movement.

Just as deaf and hearing subjects differentially weighted the dimensions of the group solution for lexical movement, so did they differentially weight the dimensions of the group solution for inflectional movement. Figure 9 presents the mean weights for deaf and for hearing subjects for each dimension of the solution. The figure shows that the deaf and hearing subjects differ dramatically in the way they weight the four dimensions. The dimension most important to the deaf, cyclicity, is least important to the hearing subjects, whereas the dimension most important to the hearing subjects, direction, is least important to the deaf. Dimensions 2 and 4 of the solution, displacement and iteration length, seem equally weighted by deaf and hearing subjects and occur as the second and third, respectively, most weighted dimensions by each group.

A mixed-design analysis of variance was performed on the weights obtained for deaf and hearing subjects across the four dimensions. There was no significant effect of dimension $[F(3,24)=2.6$, n.s.] or of subject group $[F(1,8)=1.0$, n.s.]. The lack of reliable effects here reflects the facts that, pooled over the deaf and hearing subjects, the weights along the four dimensions did not reliably differ and that, pooled over dimensions, the mean weights of the deaf and hearing subjects did not reliably differ. Most importantly, however, the analysis yielded a highly significant interaction between subject group and dimension $[F(3,24)=6.6, p<.005]$. This interaction indicates that the deaf and hearing subjects reliably differed in their pattern of weights applied to the four dimensions. ${ }^{3}$

Figure 9 indicated that Dimensions 1, 2, and 4 of the group solution were perceptually important to the deaf subjects, whereas Dimension 3 seemed of little perceptual relevance to these subjects. Figure 10 presents the configuration in the three dimensions important to deaf subjects and thus represents perceived relationships among the inflectional movements by native ASL signers. Vertically,

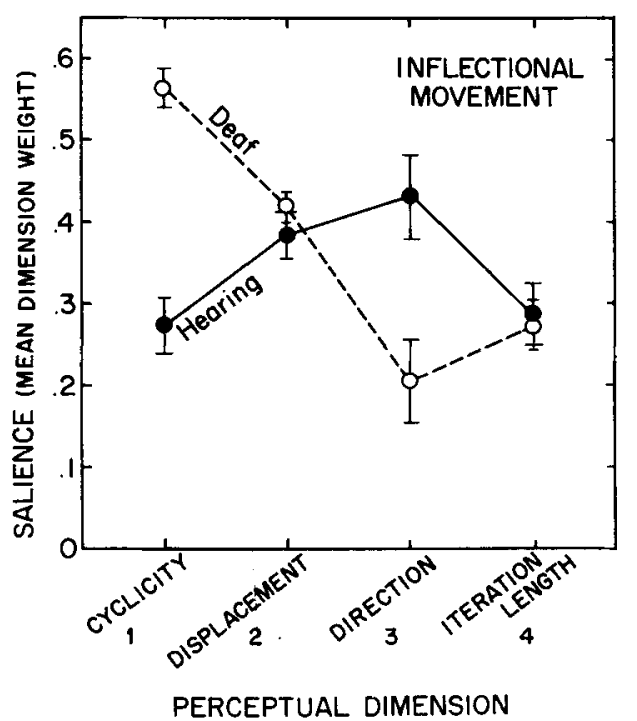

Figure 9. Perceptual sallence of each dimension of the scallng solution of inflectional movement for deaf subjects (dashed line) and for hearing subjects (solid line). 


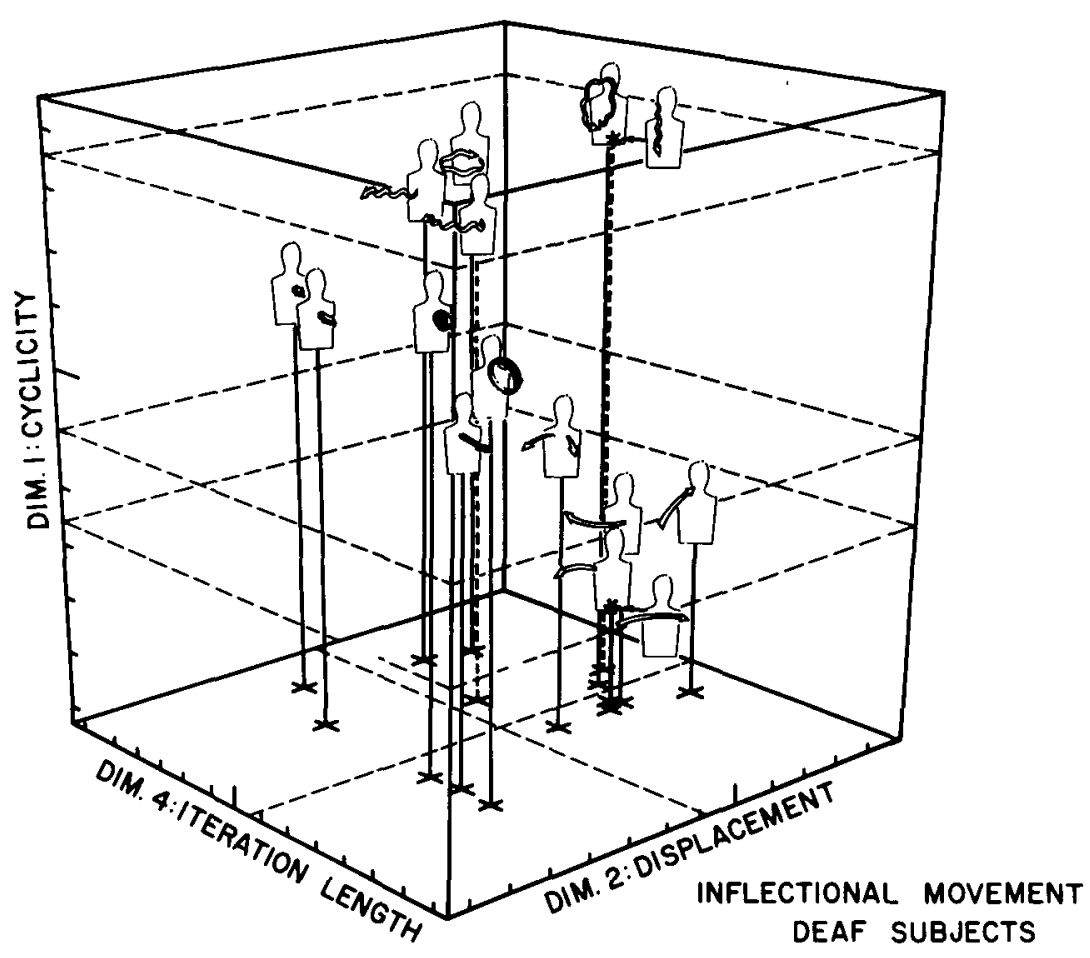

Figure 10. Configuration of stimuli in the three dimensions important to deaf subjects for infiectional movement. The dashed cross-sections in the figare are positioned to indicate the four grouplagn of atimuli along the rertical dimenion, cyclicity.

the movements are grouped on the basis of their pattern of cyclicity (single movements, two movements, reduplicated across cycles, and iterated within cycles). The five forms that are not displaced from the sagittal axis are separated from the other movements along Dimension 2, displacement. The final dimension, iteration length, then separates movements on the basis of the length of an iterated movement. The figure reveals several major clusters of movements. The five uppermost forms (apportionative internal, seriated internal, apportionative external, seriated external, and exhaustive) are seen not only to share a pattern of cyclicity that involves iterations within a cycle, but also to share displacement off the sagittal axis and iterated movements of short length. Similarly, the five movements directly below these along the vertical dimension (incessant, habitual, durational, continuative, and iterative) share not only a pattern of movement that involves reduplicated movement cycles, but also movement along the sagittal axis. The next vertical section contains the dual inflection, which has exactly two iterations. The figure shows this movement to be quite distinct from the others. Finally, the four movements closest to the base of the cube in Figure 10 also form a tight class; all are single, nonrepeated movements, all are displaced from the sagittal axis, and the spatial paths of all the movements are relatively long.

Individual deaf and hearing subjects, as well as the groups as a whole, differed in the pattern of weights applied to the four dimensions. Figure 11 presents the distribution of combined weights on Dimensions 3 and 4 versus the combined weights on Dimensions 1 and 2 for the 20 input matrices. Strikingly, this distribution falls into groups based on whether the subjects were hearing or deaf. The nine points below the horizontal dashed line in the figure show relatively high combined weights on Dimensions 1 and 2, and all represent deaf subjects. Furthermore, the 11 points above the dashed line show relatively high combined weights on $\mathrm{Di}$ mensions 3 and 4 , and 10 of these points represent hearing subjects. The one exception to this complete bifurcation of the distribution into deaf and hearing subjects (D2B) comes from the one subject, of all those run, with the least reliable pattern of weights (as seen in the very large separation of Subject D2's replications, A and B). Otherwise, the pattern of weights for a given subject seems quite reliable: the two replications for a given subject tend to be close together. Several deaf subjects do show, however, somewhat greater reliability of their combined weights on Dimensions 1 and 2 than on Dimensions 3 and 4.

\section{DISCUSSION}

The scaling solutions clearly indicated that deaf and hearing subjects perceived both lexical and in- 


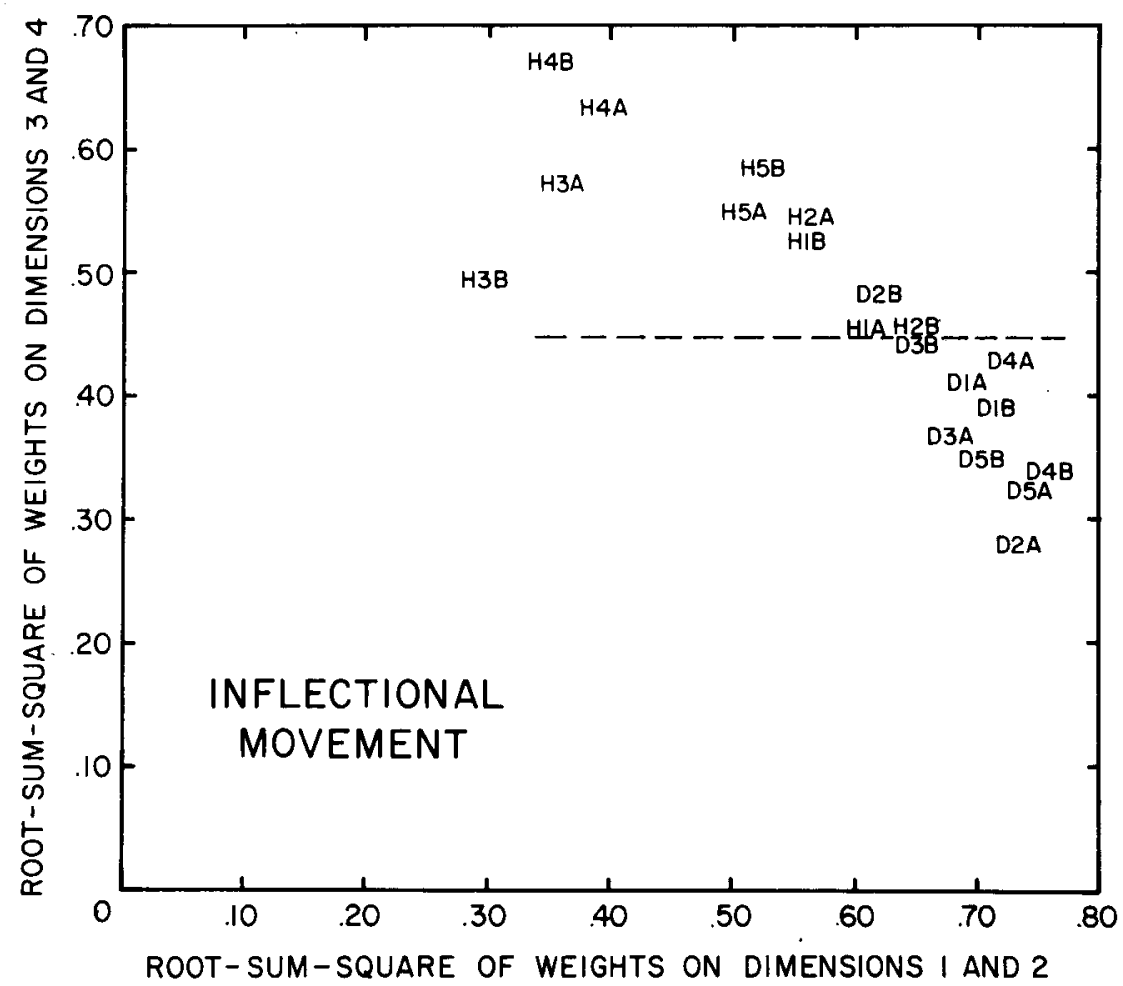

Figure 11. Root enm equares of subject welghts on D/mensions 2 and 4 verius root sum squares of wubject wetghts on Dimentons 1 and 3.

flectional movement in terms of a limited set of underlying dimensions. Movements at each of the two linguistic levels, then, are perceived not as holistically different from one another or as randomly related, but rather are perceived in terms of shared relationships among elements of a system.

\section{Relation to Formal Linguistic Models}

Four dimensions were extracted for lexical and for inflectional movement. At the lexical level, dimensions of repetition, plane, arcness, and direction accounted for $70 \%$ of the variance in the similarity judgments. Some dimensions of the scaling solution may be based solely on the visual properties of the movement forms, whereas others may be based in part on the role the movements play in the linguistic system. Dimension 1 of the lexical solution, repetition, captures a movement attribute important to the linguistic description of lexical movement. Stokoe et al. (1965) denoted the value of repetition for each sign in their dictionary, and, indeed, Klima and Bellugi (1979) argued that repetition must be significant to the structure of lexical signs because it is necessary to understanding how signs appear under certain grammatical processes. Since repetition of movement plays a role in the structure of lexical signs, this perceptual dimension or feature maps quite directly onto a linguistic one.
Dimension 2, plane, separates movements according to whether they occur primarily in a horizontal, frontal, or some other plane with respect to the signer's body. Since planar locus can minimally distinguish lexical signs (Klima \& Bellugi, 1979), Dimension 2 of the scaling solution also seems relevant to the internal organization of lexical signs. However, some of the movements (e.g., pronating and supinating movements) only happen to occur in a horizontal plane due to the particular signs used, and by no means necessarily occurred there. Thus, Dimension 2, plane, does not seem to capture an important linguistic parameter quite so clearly as does Dimension 1. Dimension 3 of the scaling solution, arcness, reflects variation in the degree of arcness of the movement path and, like Dimension 2, does not seem to capture an important linguistic parameter quite so clearly as did Dimension 1. However, Stokoe et al. (1965) did categorize lexical movements in terms of movement in straight lines and movement in circles, and Supalla (1980) considered straight versus arced versus circular movement paths important to a particular subset of ASL signs.

Finally, Dimension 4, direction, reflects variation in the degree of rightward or leftward displacement of the movement. Even though directional movements can minimally contrast lexical signs, the clustering of movements along Dimension 4 
does not relate to any posited linguistic parameter. For example, although circular movements, movements toward and away from the signer, and rotational movements can have rightward or leftward components, the rightward or leftward movement of these forms has no significance in the linguistic system, but rather is incidental to the movement. Importantly, depending upon the dimensions' linguistic relevance, dimensions of the scaling solution were of differential salience to deaf and hearing subjects. This difference indicates that perception of relationships among movements depends on linguistic experience, a topic to which we later turn.

Four dimensions were also extracted for the inflectional movements, dimensions of cyclicity, displacement, direction, and iteration length. Three of these were at least moderately weighted by the deaf subjects, cyclicity, displacement, and iteration length, whereas all four dimensions received moderate weights by the hearing subjects. Klima and Bellugi (1979) have proposed 11 spatial and temporal dimensions that underlie the structure of inflectional movement. These dimensions capture movement attributes of planar locus, geometric pattern, direction, manner, rate, tension, evenness, size, contouring, cyclicity, and doubling of the hands.

The 15 inflections used as stimuli span multiple values of all these attributes, except for doubling of the hands. The recovered dimensions reflect the most important perceptual divisions, perhaps even the ones that are extracted first. Dimension 1 of the scaling solution was cyclicity. This dimension is important to the internal organization of inflections and reflects whether the movement is articulated once, articulated twice, reduplicated across cycles (as in the inflections for temporal aspect), or reiterated within a cycle (as in the inflections for distributional aspect). Dimension 2 of the scaling solution, displacement, is likewise important to the linguistic patterning of the inflections. For the set of 15 inflections of the present study, displacement from the sagittal axis is a formational attribute that distinguishes inflections for temporal aspect from those of other grammatical categories.

Dimension 3 of the scaling solution, direction, was the dimension most highly weighted by the hearing subjects and least highly weighted by the deaf subjects; it specifies whether or not the movement path is directed to the right or to the left of the TV screen. This dimension apparently captures the same distinction as Dimension 4 of the lexical solution, and, as for that dimension, the particular groupings of movements are not relevant linguistically. Finally, Dimension 4 of the scaling solution, iteration length, which is weighted only moderately, but equally, by deaf and hearing subjects, separates inflections with a very short path movement for each articulation from the rest. This dimension, weighted equally by deaf and hearing subjects, may well be primarily psychophysically determined.

Thus, in answer to the first question posed in the introduction, some of the dimensions of the scaling solutions for lexical and inflectional movements relate to linguistically relevant dimensions, whereas others seem based solely on salient visual properties of the movement forms. For example, Dimension 1, repetition, of the lexical solution was a dimension clearly relevant to the structure of lexical signs in ASL, whereas Dimension 4, direction, was not. Importantly, the deaf subjects placed extremely high weight on the former dimension and negligible weight on the latter. Similarly, for the inflectional movements, the dimensions of cyclicity and displacement were related to linguistic dimensions, whereas the dimensions of direction and iteration length seemed based solely on the visual properties of the movement forms. Once again, dimensions relevant to the linguistic organization of the movement forms were salient to the deaf subjects; of the two dimensions unrelated to this organization, one was perceptually salient only to the hearing subjects, and the other was equally salient to both groups.

Data from hearing subjects allow a fuller understanding of the relation of perceptual to linguistic dimensions. Their results show that it is not the case that the linguistic dimensions are simply the most salient ones psychophysically. For example, cyclicity, a dimension clearly relevant to the formational structure of ASL inflections, was weighted least highly by the hearing subjects and most highly by the deaf subjects. If psychophysical salience were the only determining factor, the hearing and deaf subjects should have had roughly equal weight on the dimension. The salience of some linguistically relevant dimensions is predicted by their psychophysical salience, but this is not necessarily the case. We also note that the hearing subjects placed high weight on the lexical dimension, repetition, and low weight on the inflectional dimension, cyclicity. If these two dimensions were in any way one and the same, their salience should not have been so dramatically different to the hearing subjects. This brings us to the second question, whether dimensions underlying the perception of lexical movement are the same as dimensions underlying perception of inflectional movement.

\section{A Possible Two-Tiered "Phonetic" Structure}

The dimensions underlying perception of inflectional movement for both deaf and hearing subjects were in general not the same as those underlying 
perception of lexical movement. ${ }^{4}$ Inflectional dimensions of cyclicity, displacement, and iteration length did not occur at the lexical level. Only the dimension of direction was common to both levels. Thus, the major dimensions of the psychological representation of movement forms at the two linguistic levels differ. These perceptual data support the claim from linguistic analysis that the formational fabrics of the two levels differ (Bellugi, 1980; Klima \& Bellugi, 1979).

In a previous study of the physical characteristics of lexical and inflectional movements (Bellman, Poizner, \& Bellugi, in press), we also found a difference in the "phonetic" structure of lexical and inflectional movement. In that study, algorithmic procedures were developed to apply templates uniformly to digitized lexical and inflectional movements. These movements were a subset of those used in the present study. Discriminant analyses performed on the output of the template measurements revealed that the physical characteristics that served to differentiate one inflection from another differed from those that differentiated lexical movements. A particularly dramatic method of revealing, from perceptual data, the nature of any multilayered "phonetic" structure in ASL would be to perform a single scaling that includes both lexical and inflectional movements. (Due to the extremely large number of triads required, this cannot readily be done using the method of triadic comparisons.) If the dimensions underlying the perception of movement at the two levels differed, then lexical and inflectional movements would be separated in one and the same scaling solution. The present data clearly suggest that such a result might occur. Current studies in our laboratory are designed to test this possibility.

Bellugi (1980) suggested that if a language has its basic lexical items and its grammatical inflections simultaneously displayed, then it makes sense to have a way to keep the two layers separate; different inventories of building blocks (or combinations thereof) for the two co-occurring layers would provide a mechanism for this separation. A difference in the formational fabric of forms at the two linguistic levels in ASL might reflect the large number of dimensions available for a visual-gestural system from which a visual language could build its forms. We might then in general predict that sign languages would tend to differ from spoken languages in this regard, due to their roots in the visual modality.

\section{Effects of Linguistic Experience}

Perceptual dimensions important to the hearing subjects provide clues to the natural visual categories into which sign movements fall. Apparently, movement repetition and cyclicity, direction of movement, plane of movement, degree of arcness, displacement from the sagittal body axis, and length of movement are salient psychophysical properties to observers for whom these stimuli are not part of a phonological system. Turning to the final question posed in the introduction, the data clearly show that these natural visual categories are of different perceptual salience to deaf signers who have acquired ASL as a first and primary language. The pattern of dimensional salience of the deaf subjects differed substantially from that of the hearing subjects at both the lexical and inflectional levels. This difference is strikingly illustrated by the complete separation of the groupings of deaf and hearing subjects in the analysis of individual subject differences (Figures 7 and 11).

The fact that the pattern of dimension weights differed significantly for deaf and hearing subjects at both linguistic levels, coupled with the more direct relation for deaf than for hearing subjects between perceptually important dimensions and linguistically relevant ones, argues strongly that experience with a visual-gestural language can affect perception. Experience with spoken language likewise can affect the perception of speech sounds, even when linguistic categorizations run counter to natural auditory categories. As was previously mentioned, infants can discriminate acoustic differences that cue the distinction between $/ r /$ and /1/ (Eimas, 1975), as can English-speaking adults, in whose language the distinction is phonologically contrastive. However, the distinction between $/ r /$ and $/ 1 /$ is not contrastive in Japanese phonology, and, indeed, Japanese-speaking adults fail to discriminate the acoustic differences for this distinction. In a review of the role of linguistic experience on the perception of speech, Strange and Jenkins (1979) conclude that "it appears that appreciable modification of innate sensitivities takes place over the formative years while one acquires his native language" (p. 161). The present data provide the first evidence that acquisition of a visual-gestural language can likewise modify perception of its language elements, despite the radical differences between auditory and visual processing. ${ }^{5}$ This is not to say that such modification would be expected to occur everywhere in ASL; in fact, no such modification has yet been found for the static parameters of spatial location and of hand configuration (Poizner \& Lane, 1978; Stungis, 1981), and, indeed, neither of these static parameters is perceived categorically by native signers (Newport, 1982). However, the present data make clear that for movement, linguistic experience with a visual-gestural language can modify some natural visual categories into which these movements fall. Since similar effects 
of language experience on perception occur for spoken language, the phenomenon does not depend on the particular transmission modality, be it spoken or signed, but rather can be a more general consequence of acquiring a formal linguistic system.

\section{REFERENCE NOTES}

1. Bellugi, U., \& Klima, E. S. The acquisition of three morphological systems in American Sign Language. (Papers and Reports on Child Language Development, Vol. 21, K1-35). Stanford University, 1982.

2. Loomis, J., Poizner, H., Bellugi, U., Blakemore, A., \& Hollerbach, J. Computer graphic modelling of American Sign Language. Unpublished manuscript, The Salk Institute, 1982.

3. Pruzansky, S. How to use SINDSCAL. A computer program for individual differences in multidimensional scaling. Murray Hill, N.J: Bell Telephone Laboratories, 1975.

4. Kruskal, J. B., Young, F. W., \& Seery, J. B. How to use KYST-2A, a very flexible program to do multidimensional scaling and unfolding. Murray Hill, N.J: Bell Telephone Laboratories, 1978.

\section{REFERENCES}

Aslin, R. N., \& Prsoni, D. B. Effects of early linguistic experience on speech discrimination by infants: A critique of Eilers, Gavin, and Wilson (1979). Child Development, 1980, 51, 107-112.

Bellman, K., Poizner, H., \& Bellugi, U. Invariant characteristics of some American Sign Language morphological processes. Discourse Processes, in press.

Belluol, U. The structuring of language: Clues from the similarities between signed and spoken language. In U. Bellugi \& M. Studdert-Kennedy (Eds.), Signed and spoken language: Biological constraints on linguistic form (Dahlem Konferenzen). Weinheim/Deerfield Beach, Fla: Verlag Chemie, 1980.

Belluat, U., KLIma, E. S., \& Siple, P. Remembering in signs. Cognition: International Journal of Cognitive Psychology, 1975, 3, 93-125.

Carroll, J. D., \& Arabie, P. Multidimensional scaling. Annual Review of Psychology, 1980, 31, 607-649.

Carroll, J. D., \& Chang, J. J. Analysis of individual differences in multidimensional scaling via an N-WAY generalization of "Eckart-Young" decomposition. Psychometrika, 1970, 35, 283-319.

EimA8, P. D. Auditory and phonetic coding of the cues for speech: Discrimination of the [r-l] distinction by young infants. Perception \& Psychophysics, 1975, 18, 341-347.

Frscher, S., \& Gough, B. Verbs in American Sign Language. Sign Language Studies, 1978, 18, 17-48.

Hartigan, J. A. Clustering algorithms. New York: Wiley, 1975.

HELM, C. E. A multidimensional ratio scaling analysis of perceived color relations. Journal of the Optical Society of America, 1964, 54, 256-262.

Johansson, G. Visual perception of biological motion and a model for its analysis. Perception \& Psychophysics, 1973, 14, 201-211.

JoHnson, S. C. Hierarchical clustering schemes. Psychometrika, 1967, 32, 241-254.

JuLEsz, B., \& Hinsh, I. J. Visual and auditory perceptionAn essay of comparison. In E. E. David \& P. B. Denes (Eds.), Human communication: A unified view. New York: McGrawHill, 1972.
Jusczyk, P. W., Pisoni, D. B., Walley, A., \& Murray, J. Discrimination of relative onset time of two component tones by infants. Journal of the Acoustical Society of America, 1980, 67, 262-270.

Krima, E. S., \& Bellugi, U. The signs of language. Cambridge, Mass: Harvard University Press, 1979.

KRUSKal, J. B. Multidimensional scaling by optimizing goodness of fit to a nonmetric hypothesis. Psychometrika, 1964, 29, 1-27. (a)

KRU8KAL, J. B. Nonmetric multidimensional scaling: A numerical method. Psychometrika, 1964, 29, 115-129. (b)

Lane, H., \& Grosjean, F. (Eds.) Recent perspectives on American Sign Language. Hillsdale, N.J: Erlbaum, 1980.

Levelt, W. J. M., Van De Geen, J. P., \& Plomp, R. Triadic comparisons of musical intervals. British Journal of Mathematical and Statistical Psychology, 1966, 19, 163-179.

Liberman, A. M., Cooper, F. S., Shankweiter, D. S., \& Studdert-Kennedy, M. Perception of the speech code. Psychological Review, 1967, 74, 431-461.

Miyawaki, K., Strange, W., Verbrugoe, R. R., Liberman, A. M., Jenkins, J. J., \& Fujtmura, 0 . An effect of linguistic experience: The discrimination of $/ r /$ and $/ 1 /$ by native speakers of Japanese and English. Perception \& Psychophysics, 1975, 18, 331-340.

Newkirk, D., Klima, E. S., Pedersen, C. C., \& Bellugi, U. Linguistic evidence from slips of the hand. In V. Fromkin (Ed.), Errors in linguistic performance. New York: Academic Press, 1980.

NEWPORT, E. S. Task specificity in language learning? Evidence from speech perception and American Sign Language. In L. R. Gleitman \& E. Wanner (Eds.), Language acquisition: The state of the art. New York: Cambridge University Press, 1982.

Pisoni, D. B. Identification and discrimination of the relative onset time of two component tones: Implications for voicing perception in stops. Journal of the Acoustical Society of America, 1977, 61, 1352-1361.

Poizner, H., Battison, R., \& Lane, H. Cerebral asymmetry for American Sign Language: The effects of moving stimuli. Brain and Language, 1979, 7, 351-362.

Poizner, H., Bellugi, U., \& Lutes-Driscoll, V. Perception of American Sign Language in dynamic point-light displays. Journal of Experimental Psychology: Human Perception and Performance, 1981, 7, 430-440.

Poizner, H., Bellugi, U., \& Tweney, R. D. Processing of formational, semantic, and iconic information of signs from American Sign Language. Journal of Experimental Psychology: Human Perception and Performance, 1981, 7, 1146-1159.

Poizner, H., Klima, E. S., Bellugi, U., \& Livingston, R. Motion analysis of grammatical processes in American Sign Language. SIGGRAPH/SIGART workshop on motion: Representation and Perception, in press.

Poizner, H., \& Lane, H. Discrimination of location in American Sign Language. In P. Siple (Ed.), Understanding language through sign language research. New York: Academic Press, 1978.

Poizner, H., Newktrk, D., Bellual, U., \& Ktima, E. S. Representation of inflected signs from American Sign Language in short-term memory. Memory \& Cognition, 1981, 9, 121-131.

Schwartz, J., \& TAllal, P. Rate of acoustic change may underlie hemispheric specialization for speech perception. Science, 1980, 207, 1380-1381.

ShEPARD, R. N. The analysis of proximities: Multidimensional scaling with an unknown distance function, I. Psychometrika, $1962,27,125-140$. (a)

ShePARD, R. N. The analysis of proximities: Multidimensional scaling with an unknown distance function, II. Psychometrika, 1962, 27, 219-246. (b)

She PA RD, R. N. Multidimensional scaling, tree-fitting, and clustering. Science, 1980, 210, 390-398. 
Siple, P. (Ed.). Understanding language through sign language research. New York: Academic Press, 1978.

Stokoe, W. C., Casterline, D. C., \& Croneberg, C. G. A dictionary of American Sign Language. Washington, D.C: Gallaudet College Press, 1965.

Stranae, W., \& Jenkins, J. J. The role of linguistic experience in perception. In H. L. Pick, Jr., \& R. D. Wald (Eds.), Perception and experience. New York: Plenum, 1979.

STunars, J. Identification and discrimination of handshape in American Sign Language. Perception \& Psychophysics, 1981, 29, 261-276.

Supalla, T. Morphology of verbs of motion and location in American Sign Language. In F. Caccamise \& D. Hicks (Eds.), Proceedings of the Second National Symposium on Sign Language Research and Teaching. Silver Spring, Md: National Association of the Deaf, 1980.

Supalin, T., \& Newpozt, E. How many seats in a chair? The derivation of nouns and verbs in American Sign Language. In P. Siple (Ed.), Understanding language through sign language research. New York: Academic Press, 1978.

Wilbur, R. American Sign Language and sign systems: Research and applications. Baltimore, Md: University Park Press, 1979.

Wish, M., \& CArroll, J. D. Application of individual differences scaling to studies of human perception and judgment. In E. C. Carterette \& M. P. Friedman (Eds.), Handbook of perception (Vol. 2). New York: Academic Press, 1974.

\section{NOTES}

1. Lexical signs are denoted by English glosses in full capitals, for example, HOME. Multiword glosses for single-sign forms are hyphenated, as in GIVE-A-OIFT. Superscript labels, as in OIVEA-GIFT ${ }^{\text {(multiple), }}$ refer to specific inflectional processes that signs have undergone.

2. The difference in the psychological representation of the lexical movements for deaf as opposed to hearing observers is also clearly evident when judgments of deaf and hearing subjects are separately scaled. Nonparametric multidimensional scalings using the KYST computer program (Kruskal, Young, \& Seery, Note 4) were performed separately on the grouped hearing and grouped deaf data. The use of a nonparametric scaling, furthermore, provides a check on the metric assumptions of SINDSCAL. SINDSCAL assumes a particular relationship between the distances separating stimuli in the scaling solution and the obtained similarity scores, namely, a linear relationship. KYST assumes no particular function relating the two, other than that the function be monotonically decreasing. KYST thus affords the opportunity to check the SINDSCAL assumption of linearity and, in the process, to provide a strong test of the effect of single versus separate scalings of the data. KYST scalings of the judgments of the deaf subjects yielded a two-dimensional solution, whose dimensions were repetition and arcness. These dimensions were the same two dimensions that the INDSCAL solution showed to be important to the deaf subjects, when judgments of deaf and hearing subjects were scaled together. KYST scalings of judgments of the hearing subjects differed from those of the deaf subjects. The hearing subjects had a two-dimensional solution with dimensions of repetition and direction. These two dimensions were two of the three most highly weighted dimensions of the hearing subjects from the SINDSCAL solution. As in that solution, direction applied only to the hearing subjects, not to the deaf. The results of these separate scalings of deaf and hearing subjects thus demonstrate three points. In the first place, SINDSCAL's metric assumption could not have artifactually produced the results, since very similar solutions were obtained with nonmetric scalings. Second, the difference in the psychological representation of lexical movement for deaf and hearing subjects is not due to grouping deaf and hearing data together in a SINDSCAL analysis.
Third, pooling deaf and hearing subjects together in the SINDSCAL analysis did not affect the nature of the dimensions recovered for each group individually. Separate KYST scalings for each group reflected the same dimensions important to each group in the SINDSCAL analysis, and, hence, reflected the same differences between the groups. A single SINDSCAL analysis provides, of course, a much more powerful way for quantifying differences between groups as well as allows more dimensions to be recovered (see discussion in text).

3. As for lexical movements, separate KYST scalings of deaf and hearing subjects for inflectional movement revealed different dimensions for the two groups, dimensions that also appeared in the SINDSCAL analysis. Both groups showed two-dimensional solutions. Dimensions for the deaf subjects were cyclicity (with the same four divisions as in that dimension from SINDSCAL) and displacement. These two dimensions were exactly the same two dimensions most heavily weighted by the deaf subjects in the SINDSCAL solution. The solution of the hearing subjects differed from that of the deaf subjects. The dimensions for the hearing subjects were displacement and iteration length, two of the three dimensions that were most highly weighted by hearing subjects in the SINDSCAL solution. Thus, pooling deaf and hearing subjects together in the SINDSCAL analysis did not produce the differences between groups or affect the nature of the recovered dimensions for each group; likewise, SINDSCAL's metric assumption could not have artifactually produced the results.

4. The lexical and inflectional movements used in the experiment are naturally a subset of all lexical and inflectional movements in ASL. The movements were selected, however, to be representative of movements at each level. The inflections spanned categories of temporal aspect, grammatical number, person, and distributional aspect. Furthermore, they spanned multiple values of all 11 spatial and temporal dimensions, except doubling of the hands, proposed on linguistic grounds to underlie the structure of inflectional movement (Klima \& Bellugi, 1979). All have path movement (movement of the hand and arm through space). Likewise, the lexical movements represent all the lexical movement primes listed in Stokoe et al. (1965) that have path movement except those that involve two hands (this excludes movements such as movements only of the fingers or twisting movements of the hand).

5. The dependence of the perception of speech sounds on the linguistic experience of the listener has, of course, nothing whatever to do with the meanings of the sounds, for which there are none, but rather on the usage of the sounds in the respective phonological systems. Similarly, the differences in perception of ASL movement by deaf signers and by naive hearing subjects have nothing to do with meaning. At the lexical level, movement is only one of several co-occurring parameters that form meaningful signs. At the inflectional level, movements do represent grammatical morphemes, but the data indicate that the subjects made judgments on the basis of movement form. To take just one example, we note the grouping of stimuli along Dimension 1, cyclicity. The cyclic nature of the movements is not completely divorced from meaning and thus makes possible a strong test of whether judgments were based on form or on meaning. Inflections that in. dicate recurrence of events over time have more than one articulation, as do most of the inflections that indicate action to a plural, as opposed to a singular, object of the verb. However, one inflection that indicates a plural object of the verb, the multiple, is made with only one articulation. This inflection was positioned along Dimension 1 of the scaling solution with inflections having single articulation, rather then with inflections indicating a plural object of the verb (which all had repeated articulations).

A second consideration in interpreting the present experiment is that multidimensional scaling of triadic comparisons is a different procedure from that used to assess perception of the $/ r /-/ l /$ contrast by Japanese and American listeners. Multidimensional scaling, however, has been amply demonstrated to be relevant to perception. For example, Wish and Carroll (1974) performed an 
INDSCAL scaling on some triadic comparisons of color similarity collected by Helm (1964). They performed a single scaling on judgments from both normal and color-deficient subjects. The scaling captured, in an elegant way, already known psychophysical relations among colors, both for the normal and color-deficient subjects. The dimension weightings for the color-deficient subjects corresponded to their known color weaknesses. Since the dimen- sions of this solution and those of other applications correspond so well to known perceptual dimensions when we have a priori knowledge of the dimensions, there can be little doubt that these analyses reveal how subjects perceive stimuli.

(Manuscript received May 3, 1982; revision accepted for publication December $14,1982$. 